\title{
Telechelics Based on Catalytic Alternating Ring-Opening Metathesis Polymerization
}

\author{
Subhajit Pal, Mahshid Alizadeh, and Andreas F. M. Kilbinger*(•) \\ Department of Chemistry, University of Fribourg, Chemin du Musée 9, CH-1700 Fribourg, Switzerland
}

Supporting Information

\begin{abstract}
We describe a protocol to synthesize alternating telechelic ROMP copolymers of 7-oxa-norbornene derivatives and cycloalkenes under catalytic conditions. These copolymers were synthesized using Grubbs' second-generation catalyst. The sterically less hindered backbone double bonds of the resulting alternating copolymers facilitate the chain transfer (secondary metathesis) reactions. In the presence of symmetrical chain transfer agents (CTA), alternating copolymers could be synthesized catalytically. This procedure allows the synthesis of telechelic polymers based on potentially functional 7-oxanorbornene derivatives under thermodynamic equilibrium conditions. The molar mass of the alternating copolymer was controlled by the monomer to CTA ratio. The end group of the copolymers synthesized in the catalytic manner was addressed by the CTA functionality, yielding telechelic copolymers in excellent yields. ${ }^{1} \mathrm{H}$ NMR spectroscopy, MALDI-ToF mass spectrometry, and SEC analysis confirmed the chemical identity of the alternating telechelic copolymers with excellent control over the molar mass.
\end{abstract}

$\mathrm{W}$ ell-defined catalysts that are often capable of being handled in air based mainly on ruthenium and molybdenum have been developed by Grubbs ${ }^{1,2}$ and Schrock. ${ }^{3}$ As these are often tolerant toward many functional groups and, ${ }^{4-7}$ additionally, available commercially, ring-opening metathesis polymerization has become a popular polymerization method for the synthesis of highly functional polymers. $^{8-10}$

ROMP polymers have applications in many different areas, for example, as active therapeutics ${ }^{11}$ or materials for photonic crystals. $^{12}$ Slugove and co-workers synthesized ROMP polymers that can be used as separators in lithium-ion batteries. $^{13}$ ROMP polymers for fluorescence imaging of cancer cells were reported by the Wu group. ${ }^{14}$ Recently, Choi and co-workers prepared semiconducting nanoribbons via metathesis polymerization. ${ }^{15}$

In a classical living ROMP, the metal carbene complex acts as an initiator, with each complex generating exactly one polymer chain. As a result, stoichiometric catalyst loadings are required with respect to the number of polymer chains synthesized. Use of a stoichiometric amount of toxic and expensive catalyst can render the process noneconomical and environmentally unfriendly. This is the case if shorter polymer chains are targeted for which a higher initiator-to-monomer ratio is required. Furthermore, removal of metal contaminations from the polymer can be challenging. However, numerous approaches have been reported to reduce the metal contamination in metathesis polymers, either by scavenging, chromatography, oxidation, chelation, use of solid supported catalysts or via metal free conditions. ${ }^{16-21}$ All these methods require either postpolymerization treatment with an excess of reagents, synthesis of specialized solid supported catalysts, or are restricted to certain monomers in the metal-free approach. As a result, metal contamination is expected to be one of the limitations of ROMP polymers in several applications. ${ }^{22-24}$

Metathesis polymers can also be prepared using only catalytic amounts of metal carbene complexes. In a catalytic ROMP, each metal carbene complex is capable of producing more than one polymer chain via repeated chain transfer to an additive, the chain transfer reagent (CTA). Early examples for the synthesis of ROMP polymers using catalytic amounts of metal carbene complexes were reported by Hillmyer and Grubbs. $^{25-28}$ More recently, the Guillaume group used this approach to prepare polymers catalytically. ${ }^{29}$

Common to all these examples are monomers with sterically unhindered double bonds, such as cyclooctadiene (COD) or cyclooctene (COE), polymerized in the presence of a symmetrical chain transfer agent (CTA), using catalytic amounts of metal carbene complexes. The molar mass of the polymers was controlled by the monomer to CTA ratio under thermodynamic equilibrium conditions $(\boxplus \approx 2)$. This synthetic method, therefore, relies on backbiting or secondary metathesis reactions, that is, chain transfer to the polymer (to the unhindered double bonds) in order to reach a thermodynamically equilibrated state. The functionality of 
both end groups of these polymers is thus defined by the functionality present in the CTA. This approach represents, therefore, the most common method to prepare telechelic polymers via ROMP.

Consequently, the synthesis of polymers not able to undergo secondary metathesis reactions is, more difficult under catalytic conditions. ROMP polymers synthesized from norbornene and its derivatives are reluctant to undergo secondary metathesis reactions and, hence, thermodynamic equilibration is slow and sometimes impossible within the lifetime of the ruthenium carbene catalyst employed. Bielawski et al. reported the synthesis of telechelic poly(norbornene) and its derivatives with catalytic amounts of ruthenium complex. ${ }^{30,31}$ Unfortunately, only unsubstituted norbornenes give satisfactory yields of telechelic polymers at elevated temperature. Matson et al. ${ }^{32}$ reported the synthesis of catalytic telechelic ROMP polymers using norbornene based monomers via pulsed addition. This concept was exploited by us to synthesize homotelechelic poly(norbornene) derivatives under noncatalytic conditions. ${ }^{33}$

Guillaume and co-workers recently reported telechelic copolymers based on norbornene derivatives and cycloalkanes. ${ }^{34}$ However, their focus was on material properties of the telechelics, and unfortunately, molar mass control by varying the monomer/CTA ratio could not be confirmed by SEC. A kinetically controlled synthesis of heterotelechelic poly(norbornene) derivatives was later reported by us. ${ }^{35}$ In these polymers the chain length is controlled kinetically by the ratio of the rate of ring opening (propagation) to the rate of chain transfer to the CTA. In the case of highly strained monomers such as norbornene derivatives, the rate of ring opening is much higher than the rate of chain transfer to acyclic CTAs. Thus, high CTA loadings are required to increase the number of catalytic cycles. Unlike in the case of thermodynamic equilibration, the molar mass of the polymer synthesized does not equate to the monomer/CTA ratio in these cases. Therefore, poor molar mass control is typically observed under kinetic control. Reports for the synthesis of the telechelic poly(norbornene) derivatives under thermodynamic equilibration are scarce.

The controlled incorporation of norbornene derivatives into telechelic polymers is, however, very desirable, as the norbornene monomer scaffold allows straightforward functional modifications and hence the potential to synthesize main-chain functional telechelic polymers. In contrast, strained cycloalkenes such as COD or COE are typically more difficult to derivatize and functionalize. Copolymerization attempts using norbornene derivatives and cycloaklenes in the presence of CTAs are more likely to give kinetically controlled telechelics and, hence, lack the desired molar mass control. ${ }^{34}$

A solution to this problem can be found by using highly alternating copolymers of norbornene derivatives and COE/ COD. Recently, the ROMP polymerization has been highlighted as an effective tool to synthesize alternating copolymers. $^{36-40}$ There, alternating copolymers using stoichiometric amounts of metal carbene complex were reported. Here, we report the synthesis of catalytic telechelic alternating ROMP copolymers employing 7-oxa-norbornene derivatives and COE/COD at thermodynamic equilibrium.

Under elevated temperature, nonsubstituted poly(norbornene) undergoes secondary metathesis to attain thermodynamic equilibrium $(\nexists \approx 2)$, whereas for norbornene derivatives, thermodynamic equilibration is less feasible. ${ }^{30,31}$ To understand the ease of the backbiting efficiency of the metathesis catalysts toward polyoxanorbornene derivatives (Figure. 1a), we synthesized monomers M1 and M2 and chain transfer agents CTA1-3 (Scheme 1).

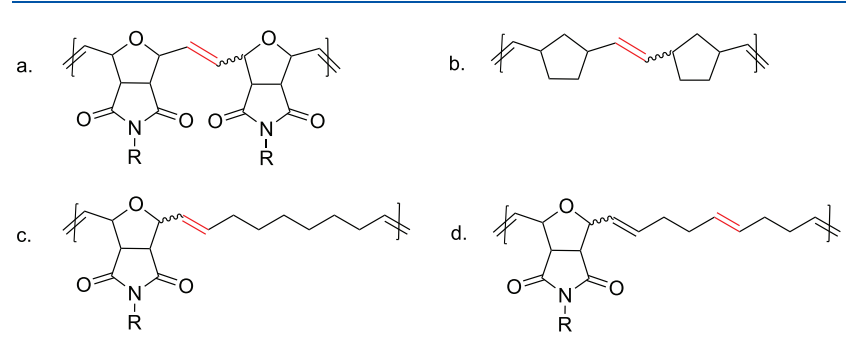

Figure 1. Reactivity order of the double bond (indicated in red) toward secondary metathesis follows $\left.\mathrm{a}^{30}<\mathrm{b}^{30}<\mathrm{c}^{*}<\mathrm{d}^{*}\right)$. *This report, see Figure 2.

Recently, Coughlin and co-worker reported the synthesis of alternating copolymers between 7-oxa-norbornene derivatives and cycloalkenes using Grubbs' first-generation $\left(\mathrm{RuCl}_{2}(=\mathrm{CHPh})\left(\mathrm{PCy}_{3}\right)_{2}\right)$ and second-generation ( tricyclohexylphosphine) (1,3-dimesitylimidazolidine-2ylidene)benzylideneruthenium dichloride, G2) catalysts. $^{41} \mathrm{We}$ hypothesized that the backbone of such alternating copolymers (Figure 1c,d) would have a higher tendency toward secondary metathesis reactions compared to the homopolymer of 7-oxanorbornene derivatives (Figure 1a). To prove our hypothesis, a control experiment was performed where monomer M1 and COE were copolymerized with $0.05 \mathrm{~mol} \%$ of $\mathbf{G 2}$ in dichloromethane at room temperature for $12 \mathrm{~h}$, followed by the addition of 50 equiv of CTA1 and heating for $24 \mathrm{~h}$ at 40 ${ }^{\circ} \mathrm{C}$. A polymer sample was taken before addition of CTA1 and after $24 \mathrm{~h}$ of equilibration in the presence of CTA1. SEC analysis revealed (see SI) that a drastic reduction in the molar mass occurred after $24 \mathrm{~h}$ of equilibration (before addition of CTA1: $M_{\mathrm{n}}=60000 \mathrm{~g} \mathrm{~mol}^{-1}, Ð=2$; after $24 \mathrm{~h}$ of equilibration in the presence of CTA1: $\left.M_{\mathrm{n}}=18000 \mathrm{~g} \mathrm{~mol}^{-1}, Ð=1.8\right)$. This indicated that cross metathesis reactions between CTA1 and the M1/COE copolymer had occurred.

As a proof of principle that the synthesis of the alternating telechelic copolymers of 7-oxa-norbornene derivatives under thermodynamic equilibration can be achieved, a set of experiments was performed varying the monomer to CTA ratio. Monomer M1 and COE were copolymerized in the presence of CTA1 using G2 in dichloromethane for $36 \mathrm{~h}$ at 40 ${ }^{\circ} \mathrm{C}$.

A linear relationship between $M_{\mathrm{n}}$ (SEC, THF) and monomer/CTA1 ratio (polymers P1-4, see Table 1) was observed (Figure 2a). Surprisingly, the linear extrapolation of the data gave a positive intercept with the molar mass $\left(M_{n}\right)$ axis, suggesting insufficient thermodynamic equilibration. Nonetheless, the excellent linear fit showed that good control over the molar mass of the synthesized copolymers was obtained.

Next, we investigated the degree of alternation of the synthesized polymers according to the reported method. ${ }^{41}$ Even though 7-oxa-norbornene derivatives have a higher ring strain than COE or COD, the latter propagate faster in ROMP. Interestingly, the endo/exo mixture of 7-oxa-norbornene derivatives and COE or COD react in an alternating fashion at a higher rate of propagation than either of the corresponding homopolymerizations. ${ }^{41}$ The alternating character of the resulting copolymers was confirmed by ${ }^{1} \mathrm{H}$ NMR analysis. 
Scheme 1. Generalized Synthesis of Catalytic Alternating Telechelic Polymers by Ring-Opening Metathesis Polymerization ${ }^{a}$

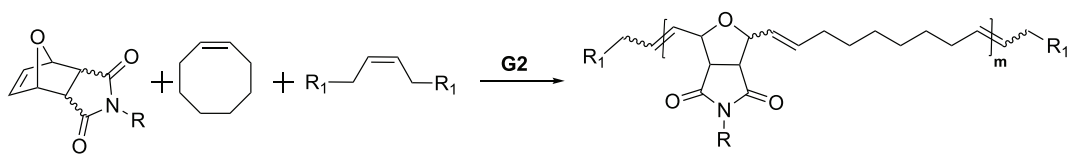

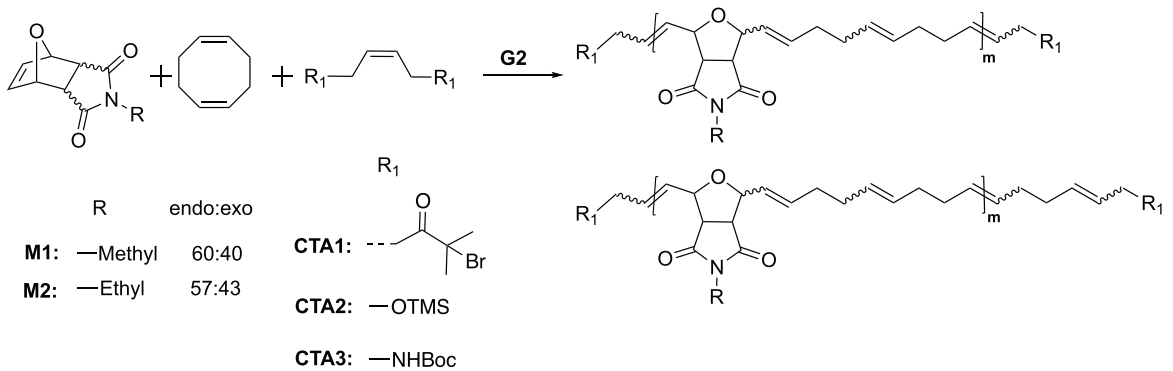

${ }^{a}$ All the reactions were carried out at $40{ }^{\circ} \mathrm{C}$ for $36 \mathrm{~h}$ at $0.5 \mathrm{M}$ monomer concentration. ${ }^{1} \mathrm{H}$ NMR spectroscopy revealed ca. $80 \%$ alternating diads for all copolymers investigated (see Figure 2 and Supporting Information).

Table 1. Polymerization Results and SEC Data for Different Polymers $^{a}$

$\begin{array}{ccccc}\text { polymer } & \text { M1/CTA/G2 } & M_{\mathrm{n}}(\text { theo }) & M_{\mathrm{n}}(\mathrm{cal}) & \oplus \\ \text { P1 } & 500: 50: 1 & 3000 & 4000 & 1.7^{b} \\ \text { P2 } & 1000: 50: 1 & 6000 & 5800 & 1.8^{b} \\ \text { P3 } & 1500: 50: 1 & 9100 & 7700 & 1.8^{b} \\ \text { P4 } & 2000: 50: 1 & 12100 & 10500 & 2^{b} \\ \text { P5 } & 500: 50: 1 & 3000 & 4700 & 2.3^{c} \\ \text { P8 } & 500: 50: 1 & 3000 & 4300 & 1.7^{b} \\ \text { P9 } & 1000: 50: 1 & 6000 & 7200 & 2^{b} \\ \text { P10 } & 1500: 50: 1 & 9000 & 10400 & 2^{b} \\ \text { P11 } & 2000: 50: 1 & 12000 & 14700 & 2^{b} \\ \text { P12 } & 500: 50: 1 & 3000 & 4600 & 2.2^{c}\end{array}$

${ }^{a}$ All reactions were carried out with G2 $(4 \mathrm{mg}, 0.0047 \mathrm{mmol})$ at 40 ${ }^{\circ} \mathrm{C}$ for $36 \mathrm{~h}$ (see Supporting Information for results using different equilibration times). For entries P1-P4, the reactions were carried out with CTA1 (93 mg, $0.24 \mathrm{mmol}$ ), monomer M1, and cyclooctene (COE). Reaction at higher temperature ${ }^{44}\left(60{ }^{\circ} \mathrm{C}\right.$ in 1,2 -dichloroethane) did not significantly improve equilibration efficiency (see Supporting Information). For entry P5, the reaction was carried out with CTA3 (68 mg, $0.24 \mathrm{mmol}$ ), monomer M1, and cyclooctene (COE). For entries P8-11, the reactions were carried out with CTA1 (93 mg, $0.24 \mathrm{mmol}$ ), monomer M1, and cyclooctadiene (COD). For entry P12, the reaction was carried out with CTA3 (68 mg, 0.24 $\mathrm{mmol}$ ), monomer M1, and cyclooctadiene (COD). ${ }^{b}$ Measured by THF SEC. ${ }^{c}$ Measured by $\mathrm{CHCl}_{3}$ SEC. ${ }^{1} \mathrm{H}$ NMR spectroscopy revealed ca. $80 \%$ alternating diads for all copolymers shown (see Supporting Information).

The ${ }^{1} \mathrm{H}$ NMR signal in the olefinic region for the copolymer was compared to the signal for the corresponding homopolymers, for each of the different monomers (Figure. 2). This showed a characteristic different set of signals, confirming the alternating nature of the copolymers, as previously shown by Coughlin and co-workers. ${ }^{41}{ }^{1} \mathrm{H}$ NMR spectroscopic investigation of the copolymerization of M1, COE, and CTA1 indicated about $80 \%$ alternating diads (Figure $2 \mathrm{~b}$ ).

MALDI-ToF mass spectrometric analysis of polymer P1 $\left(\right.$ M1 $/$ CTA1 $/$ G2 $=500: 50: 1 . M_{\mathrm{n}, \mathrm{SEC}}(\mathrm{THF})=4000 \mathrm{~g} \mathrm{~mol}^{-1}, Ð$ $=1.7$ ) and a detailed ${ }^{1} \mathrm{H}$ NMR spectroscopic analysis of polymer P5 (M1/CTA3/G2 = 500:50:1. $M_{\mathrm{n}, \mathrm{SEC}}\left(\mathrm{CHCl}_{3}\right)=$ $4700 \mathrm{~g} \mathrm{~mol}^{-1}, Ð=2.3$, see SI) proved the excellent degree of end functionalization. We also investigated the molar mass control of the alternating copolymer with CTA2 and CTA3 carrying protected alcohol and amine functional groups in combinations with different comonomers (M1 and M2) and COE (see Tables 1 and SI). Monomer M2 and COE were polymerized with CTA2 (M2/CTA2/G2 = 1000:25:1), yielding a telechelic polymer (P6) with TMS-protected alcohol groups at both chain ends of the polymer $\left(M_{\mathrm{n}, \mathrm{SEC}}\left(\mathrm{CHCl}_{3}\right)=\right.$ $14900 \mathrm{~g} \mathrm{~mol}^{-1}, Ð=1.7$, see SI). Similarly, telechelic polymer (P7) was synthesized using CTA2, monomer M1, and COE $\left(\right.$ M1 $/$ CTA2 $/ \mathbf{G} 2=2000: 25: 1 . M_{n, S E C}\left(\mathrm{CHCl}_{3}\right)=23000 \mathrm{~g}$ $\mathrm{mol}^{-1}, Ð=1.9$, see SI).

Polymers of cycloalkenes synthesized via ROMP are wellknown to achieve thermodynamic equilibrium because of easy accessibility of the backbone double bonds toward secondary metathesis reactions. ${ }^{42,43}$ In contrast to such polymers, the backbone double bonds of the alternating copolymers synthesized using M1 and COE will be less sterically accessible for the necessary chain transfer reaction (Figure 1c). We believe the steric crowding around the backbone double bonds diminishes the rate of backbiting in the alternating copolymers P1-7, leading to insufficient thermodynamic equilibration within the catalyst's lifetime.

To increase the accessibility of the backbone for the catalyst we next investigated cyclooctadiene (COD) instead of COE as a comonomer to synthesize alternating copolymers with M1. We hypothesized that the additional and sterically less hindered double bond within each repeat unit of the copolymer would facilitate the equilibrium process.

To verify our hypothesis, M1 and COD were copolymerized with varying monomer to CTA1 ratios. The plot of $M_{\mathrm{n}}$ (SEC, THF) versus monomer/CTA1 ratio (polymers P8-11, see Table 1) represents a linear relationship. The linear fit passed through the origin, indicating sufficient thermodynamic equilibration, as expected (Figure 2c).

The presence of characteristic ${ }^{1} \mathrm{H}$ NMR signals $(\delta=5.4-$ $5.95 \mathrm{ppm}$ ) due to cross-propagation confirmed the partially alternating nature of the copolymers (Figure 2d). Unlike the alternating copolymers based on COE and norbornene derivatives, the alternating copolymer based on COD provides an additional symmetric double bond $(\delta=5.30-5.45 \mathrm{ppm}$ in the ${ }^{1} \mathrm{H}$ NMR spectrum, Figure $\left.2 \mathrm{~d}\right)$. Using the described method, ${ }^{41}$ we estimated the amount of alternating diads of the copolymer to be $80 \%$ (Figure $2 \mathrm{~d}$ ).

MALDI-ToF mass spectrometry was performed on polymer P8 $\left(\right.$ M1 $/$ CTA1 $/ \mathbf{G 2}=500: 50: 1, M_{\mathrm{n}, \mathrm{SEC}}(\mathrm{THF})=4300 \mathrm{~g}$ 

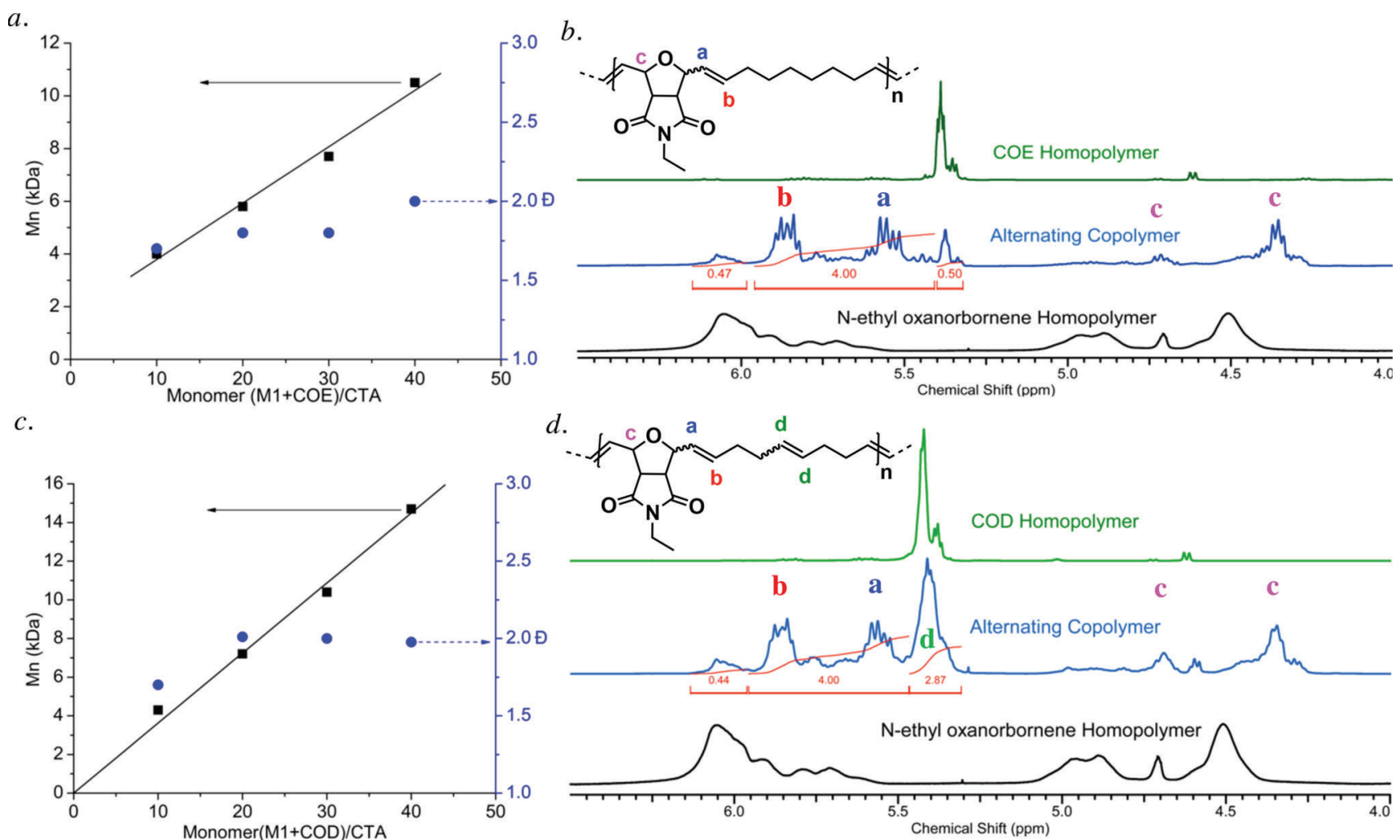

Figure 2. (a) Dependence of observed molar mass (SEC, see Table 1, entries 1-4) vs monomer (M1 + COE) to CTA1 ratio. (b) ${ }^{1} \mathrm{H}$ NMR spectrum of alternating copolymer synthesized from M1 and COE. (c) Dependence of observed molar mass (SEC, see Table 1, entries 5-8) vs monomer (M1 + COD) to CTA1 ratio. (d) ${ }^{1} \mathrm{H}$ NMR spectrum of alternating copolymer synthesized from M1 and COD. Central ${ }^{1} \mathrm{H}$ NMR spectra in (b) and (d) olefinic signals from homopropagations: $\delta=5.30-5.4 \mathrm{ppm}$ and $\delta=5.95-6.15 \mathrm{ppm}$, olefinic signals from cross-propagations: $\delta=$ 5.4-5.95 ppm. N-Ethyl oxanorbornene homopolymer signal intensities in the range from 5.5-5.9 ppm were neglected for the determination of the degree of alternation.

$\mathrm{mol}^{-1}, Ð=1.7$, see SI) as the relatively low molar mass allowed good isotopic mass resolution. The measurement confirmed the presence of the assumed end groups. ${ }^{1} \mathrm{H}$ NMR spectroscopic end group analysis was carried out for polymer P12 (M1/CTA3/G2 = 500:50:1, $M_{\mathrm{n}, \mathrm{SEC}}\left(\mathrm{CHCl}_{3}\right)=4600 \mathrm{~g}$ $\mathrm{mol}^{-1}, Ð=2.2$, see SI), which allowed good resolution of the end group signals due to its relatively low molar mass. In combination with the excellent molar mass control shown in Figure 2, we believe that a very good degree of telechelicity was achieved by this method (see also SI).

The scope of the method using COD was further investigated by synthesizing polymers P13 (M2/CTA2/G2 = 1000:25:1, $M_{\mathrm{n}, \mathrm{SEC}}\left(\mathrm{CHCl}_{3}\right)=11800 \mathrm{~g} \mathrm{~mol}^{-1}, Ð=1.9$, see SI $)$ and P14 (M1/CTA2/G2 = 2000:25:1, $M_{\mathrm{n}, \mathrm{SEC}}\left(\mathrm{CHCl}_{3}\right)=$ $26650 \mathrm{~g} \mathrm{~mol}^{-1}, Ð=1.9$, see SI) with CTA2. Both polymers showed excellent control of the molar mass via the monomer/ CTA ratio.

In conclusion, we have successfully developed a method to synthesize alternating telechelic polymers under catalytic conditions. This method allows us to synthesize telechelic poly oxanorbornene derivatives using thermodynamic equilibration. Allylic alcohol, amine, and bromo isobutyrate groups were installed at both ends of the polymers in excellent yield. ${ }^{1} \mathrm{H}$ NMR spectroscopy, SEC, and MALDI-ToF mass spectrometric analyses show a high degree of alternation, end group functionalization, and good molar mass control. This method provides an easy and efficient approach for the synthesis of main chain functional telechelic polymers. It is unique in that it allows the incorporation of readily functionalizable oxanorbornene derivatives into a telechelic polymer prepared under thermodynamic equilibrium conditions.

\section{EXPERIMENTAL SECTION: POLYMERIZATION METHOD}

An equimolar mixture of monomers (M1/M2 and COE/COD) was transferred into a vial equipped with a stir bar under an argon atmosphere. The required amount of CTA was added to the mixture of monomers. Dry, degassed dichloromethane was added to the vial to obtain a $1 \mathrm{M}$ monomer solution. Separately, a stock solution of catalyst G2 was prepared in dry, degassed dichloromethane and the required amount $(4 \mathrm{mg}, 4.7 \mu \mathrm{mol})$ of catalyst solution was added to the above vial. The reaction mixture was heated for $36 \mathrm{~h}$ at $40{ }^{\circ} \mathrm{C}$ under an argon atmosphere. The reactions were quenched with excess ethyl vinyl ether and precipitated into cold methanol to obtain a telechelic alternating polymer.

\section{ASSOCIATED CONTENT}

S Supporting Information

The Supporting Information is available free of charge on the ACS Publications website at DOI: 10.1021/acsmacrolett.9b00750.

Experimental methods, NMR spectra, and SEC data (PDF)

\section{AUTHOR INFORMATION}

\section{Corresponding Author}

*E-mail: andreas.kilbinger@unifr.ch. 


\section{ORCID}

Andreas F. M. Kilbinger: 0000-0002-2929-7499

\section{Notes}

The authors declare no competing financial interest.

\section{ACKNOWLEDGMENTS}

The authors thank Ms. Isabel Dungworth for proofreading the manuscript and the National Center of Competence in Research (NCCR Bioinspired Materials, Swiss National Science Foundation) and the Fribourg Center for Nanomaterials (FriMat) for support.

\section{REFERENCES}

(1) Grubbs, R. H. The development of functional group tolerant ROMP catalysts. J. Macromol. Sci., Part A: Pure Appl.Chem. 1994, 31, 1829-1933.

(2) Ogba, O. M.; Warner, N. C.; O’Leary, D. J.; Grubbs, R. H. Recent advances in ruthenium-based olefin metathesis. Chem. Soc. Rev. 2018, 47, 4510-4544.

(3) Buchmeiser, M. R.; Sen, S.; Unold, J.; Frey, W. N-Heterocyclic Carbene, High Oxidation State Molybdenum Alkylidene Complexes: Functional-Group-Tolerant Cationic Metathesis Catalysts. Angew. Chem., Int. Ed. 2014, 53, 9384-9388.

(4) Bielawski, C. W.; Grubbs, R. H. Living ring-opening metathesis polymerization. Prog. Polym. Sci. 2007, 32, 1-29.

(5) Kress, S.; Blechert, S. Asymmetric catalysts for stereocontrolled olefin metathesis reactions. Chem. Soc. Rev. 2012, 41, 4389-4408.

(6) Buchmeiser, M. R. Molybdenum imido, tungsten imido and tungsten oxo alkylidene N-heterocyclic carbene olefin metathesis catalysts. Chem. - Eur. J. 2018, 24, 14295-14301.

(7) Hilf, S.; Kilbinger, A. F. M. Functional end groups for polymers prepared using the ring-opening metathesis polymerization. Nat. Chem. 2009, 1, 537-546.

(8) Chen, Y.; Abdellatif, M. M.; Nomura, K. Olefin metathesis polymerization: some recent developments in the precise polymerizations for synthesis of advanced materials (by ROMP, ADMET). Tetrahedron 2018, 74, 619-643.

(9) Sutthasupa, S.; Shiotsuki, M.; Sanda, F. Recent advances in ringopening metathesis polymerization, and application to synthesis of functional materials. Polym. J. 2010, 42, 905-915.

(10) Grubbs, R. H. Handbook of Metathesis; Wiley-VCH: Weinheim, 2003.

(11) Smith, D.; Pentzer, E. B.; Nguyen, S. T. Bioactive and therapeutic ROMP polymers. Polym. Rev. 2007, 47, 419-459.

(12) Sveinbjörnsson, B. R.; Weitekamp, R. A.; Miyake, G. M.; Xia, Y.; Atwater, H. A.; Grubbs, R. H. Rapid self-assembly of brush block copolymers to photonic crystals. Proc. Natl. Acad. Sci. U. S. A. 2012, 109, 14332-14336.

(13) Kovacic, S.; Kren, H.; Krajnc, P.; Koller, S.; Slugovc, C. The use of an emulsion templated microcellular poly(dicyclopentadiene-conorbornene) membrane as a separator in lithium-ion batteries. Macromol. Rapid Commun. 2013, 34, 581-587.

(14) Xie, N.; Feng, K.; Shao, J.; Chen, B.; Tung, C. H.; Wu, L. Z. A simple, modular synthesis of bifunctional peptide-polynorbornenes for apoptosis induction and fluorescence imaging of cancer cells. Polym. Chem. 2018, 9, 77-86.

(15) Choi, I.; Yang, S.; Choi, T. L. Preparing Semiconducting Nanoribbons with Tunable Length and Width via CrystallizationDriven Self-Assembly of a Simple Conjugated Homopolymer. J. Am. Chem. Soc. 2018, 140, 17218-17225.

(16) Maynard, H. D.; Grubbs, R. H. Purification technique for the removal of ruthenium from olefin metathesis reaction products. Tetrahedron Lett. 1999, 40, 4137-4140.

(17) Ahn, Y. M.; Yang, K. L.; Georg, G. I. A convenient method for the efficient removal of ruthenium byproducts generated during olefin metathesis reactions. Org. Lett. 2001, 3, 1411-1413.
(18) Knight, D. W.; Morgan, I. R.; Proctor, A. J. A simple oxidative procedure for the removal of ruthenium residues from metathesis reaction products. Tetrahedron Lett. 2010, 51, 638-640.

(19) Farina, V.; Shu, C.; Zeng, X.; Wei, X.; Han, Z.; Yee, N. K.; Senanayake, H. K. Second-generation process for the HCV protease inhibitor BILN 2061: a greener approach to Ru-catalyzed ring-closing metathesis. Org. Process Res. Dev. 2009, 13, 250-254.

(20) Buchmeiser, M. R. Polymer-supported well-defined metathesis catalysts. Chem. Rev. 2009, 109, 303-321.

(21) Ogawa, K. A.; Goetz, A. E.; Boydston, A. J. Metal-Free RingOpening Metathesis Polymerization. J. Am. Chem. Soc. 2015, 137, $1400-1403$.

(22) Committee for Medicinal Products for Human Use. Guidelines for the Specification Limits for Residues of Metal Catalysts or Metal Reagents; European Medicines Agency, 2018.

(23) Urien, M.; Wantz, G.; Cloutet, E.; Hirsch, L.; Tardy, P.; Vignau, L.; Cramail, H.; Parneix, J. P. Field-effect transistors based on poly(3hexylthiophene): Effect of impurities. Org. Electron. 2007, 8, 727734.

(24) Nikiforov, M. P.; Lai, B.; Chen, W.; Chen, S.; Schaller, R. D.; Strzalka, J.; Maser, J.; Darling, S. B. Detection and role of trace impurities in high-performance organic solar cells. Energy Environ. Sci. 2013, 6, 1513-1520.

(25) Hillmyer, M. A.; Grubbs, R. H. Preparation of hydroxytelechelic poly(butadiene) via ring-opening metathesis polymerization employing a well-defined metathesis catalyst. Macromolecules 1993, 26, 872874.

(26) Hillmyer, M. A.; Grubbs, R. H. Chain Transfer in the RingOpening Metathesis Polymerization of Cyclooctadiene Using Discrete Metal Alkylidenes. Macromolecules 1995, 28, 8662-8667.

(27) Mahanthappa, M. K.; Bates, F. S.; Hillmyer, M. A. Synthesis of ABA Triblock Copolymers by a Tandem ROMP-RAFT Strategy. Macromolecules 2005, 38, 7890-7894.

(28) Martinez, H.; Ren, N.; Matta, M. E.; Hillmyer, M. A. Ringopening metathesis polymerization of 8 -membered cyclic olefins. Polym. Chem. 2014, 5, 3507-3532.

(29) Chauveau, C.; Vanbiervliet, E.; Fouquay, S.; Michaud, G.; Simon, F.; Carpentier, J.-F.; Guillaume, S. M. Azlactone Telechelic Polyolefins as Precursors to Polyamides: A Combination of Metathesis Polymerization and Polyaddition Reactions. Macromolecules 2018, 51, 8084-8099.

(30) Bielawski, C. W.; Grubbs, R. H. Highly Efficient Ring-Opening Metathesis Polymerization (ROMP) Using New Ruthenium Catalysts Containing N-Heterocyclic Carbene Ligands. Angew. Chem., Int. Ed. 2000, 39, 2903-2906.

(31) Bielawski, C. W.; Benitez, D.; Morita, T.; Grubbs, R. H. Synthesis of End-Functionalized Poly(norbornene)s via Ring-Opening Metathesis Polymerization. Macromolecules 2001, 34, 8610-8618.

(32) Matson, J. B.; Virgil, S. C.; Grubbs, R. H. Pulsed-Addition RingOpening Metathesis Polymerization: Catalyst-Economical Syntheses of Homopolymers and Block Copolymers. J. Am. Chem. Soc. 2009, $131,3355-3362$

(33) Hanik, N.; Kilbinger, A. F. M Narrowly distributed homotelechelic polymers in 30 minutes: Using fast in-situ prefunctionalized ROMP initiators. J. Polym. Sci., Part A: Polym. Chem. 2013, 51, 4183-4190.

(34) Michel, X.; Fouquay, S.; Michaud, G.; Simon, F.; Brusson, J.M.; Roquefort, P.; Aubry, T.; Carpentier, J.-F.; Guillaume, S. M. Tuning the rpoperties of $\alpha, \omega$-bis(trialkoxysilyl) telechelic copolyolefins from ruthenium-catalyzed chain-transfer ring-opening metathesis polymerization (ROMP). Polym. Chem. 2017, 8, 1177-1187.

(35) Liu, P.; Yasir, M.; Ruggi, A.; Kilbinger, A. F. M. One-Pot Synthesis of Heterotelechelic Polymers via Ring Opening Metathesis Polymerization. Angew. Chem., Int. Ed. 2018, 57, 914-917.

(36) Song, A.; Parker, K. A.; Sampson, N. S. Synthesis of Copolymers by Alternating ROMP (AROMP). J. Am. Chem. Soc. 2009, 131, 3444-3445.

(37) Lichtenheldt, M.; Wang, D.; Vehlow, K.; Reinhardt, I.; Kühnel, C.; Decker, U.; Blechert, S.; Buchmeiser, M. R. Alternating Ring- 
Opening Metathesis Copolymerization by Grubbs-Type Initiators with Unsymmetrical N-Heterocyclic Carbenes. Chem. - Eur. J. 2009, $15,9451-9457$.

(38) Elling, B. R.; Xia, Y. Living Alternating Ring-Opening Metathesis Polymerization Based on Single Monomer Additions. J. Am. Chem. Soc. 2015, 137, 9922-9926.

(39) Parker, K. A.; Sampson, N. S. Precision Synthesis of Alternating Copolymers via Ring-Opening Polymerization of 1-Substituted Cyclobutenes. Acc. Chem. Res. 2016, 49, 408-417.

(40) Paradiso, V.; Grisi, F. Ruthenium-Catalyzed Alternating RingOpening Metathesis Copolymerization of Norborn-2-ene with Cyclic Olefins. Adv. Synth. Catal. 2019, 361, 4133-4139.

(41) Ilker, M. F.; Coughlin, E. B. Alternating Copolymerizations of Polar and Nonpolar Cyclic Olefins by Ring-Opening Metathesis Polymerization. Macromolecules 2002, 35, 54-58.

(42) Tuba, R.; Grubbs, R. H. Ruthenium catalyzed equilibrium ringopening metathesis polymerization of cyclopentane. Polym. Chem. 2013, 4, 3959-3962.

(43) Hlil, A. R.; Balogh, J.; Moncho, S.; Su, H. L.; Tuba, R.; Brothers, E. N.; Al-Hashimi, M.; Bazzi, H. S. Ring Opening Metathesis Polymerization (ROMP) of Five-to Eight-Membered Cyclic Olefins: Computational, Thermodynamic and Experimental Approach. J. Polym. Sci., Part A: Polym. Chem. 2017, 55, 3137-3145. (44) Neary, W. J.; Kennemur, J. G. Variable Temperature ROMP: Leveraging Low Ring Strain Thermodynamics To Achieve WellDefined Polypentenamers. Macromolecules 2017, 50, 4935-4941. 